\title{
COMUNICAÇÃO POR REDE SEM FIO PARA CONTROLE DE UM MANIPULADOR ROBÓTICO
}

\author{
RENATO R. THEOBALDO ${ }^{1}$,DANIEL D.PINI ${ }^{1}$, ALINE GESUALDI-MANHÃES ${ }^{1}$ \\ 1. $8^{o}$ período do Curso de Engenharia de Automação e Controle, Departamento de Engenharia Elétrica, \\ Centro Federal de Educação Tecnologica Celso Suckow da Fonseca (CEFET-RJ) \\ Rio de Janeiro \\ E-mails: renatotheobaldo@gmail.com,daniel_ca_@hotmail.com,agesualdi@cefet-rj.br
}

\begin{abstract}
This paper presents a wireless design for a Robotic Manipulator that is under construction at CEFET/RJ by four students of the $8^{\text {th }}$ term of Automation Control Engineering. The main focus of this paper is to present the specificities of the wireless connection designed in PIC microcontroller. We present the time response results and the positive aspects of using Microcontrollers.
\end{abstract}

Keywords_ Robotic Manipulator, Wireless, TCI/IP, PIC microcontrollers, embedded systems

Resumo--O artigo explica de forma breve a tecnologia de rede sem fio e utilização da mesma em um projeto de um Manipulador Robótico. Visto que existem diversos estudos e trabalhos acerca do assunto discutido, aqui se visa abranger os principais pontos para o funcionamento pleno do Manipulador. O artigo demonstra resultados obtidos com relação a tempo de resposta e praticidade utilizando Microcontroladores.

Palavras-chave—Manipulador Robótico, Wireless, TCP/IP, Microcontroladores PIC, sistemas embarcados.

\section{Introdução}

O presente artigo faz parte de um projeto mais abrangente de um Manipulador Robótico com três graus de liberdade que realiza a identificação de alvos móveis. Manipuladores são muitos utilizados hoje na indústria automobilísticas, bélicas e até mesmo em Medicina podendo ser controlados por operadores ou de forma autônoma seguindo uma tarefa pré-estabelecida.

O objetivo desde artigo consiste em apresentar como foi projetada a comunicação de controle do usuário para o Manipulador Robótico utilizando tecnologia de rede (Forouzan 2008) sem fio (Wireless), via Microcontroladores PIC.

O Manipulador Robótico está sendo totalmente desenvolvido por quatro alunos do curso de Graduação em Engenharia de Automação e Controle do CEFET/RJ. O desenvolvimento do manipulador foi dividido em cinco partes: (i) projeto mecânico e impressão das peças; (ii) projeto do sistema embarcado para movimentação, controle e comunicação com o usuário; (iii) projeto do sistema de comunicação sem fio; (iv) projeto de controle; (v) projeto do sistema de identificação através do reconhecimento de padrões por visão computacional. O presente artigo aborda as partes (ii) e (iii) da construção.
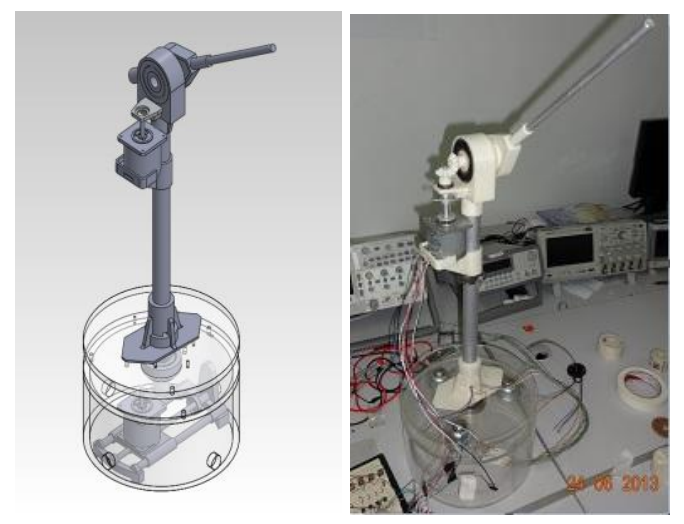

Figura 1. Manipulador em construção no programa de desenvolvimento e fisicamente construído

\section{Materiais e Métodos}

Inicialmente a comunicação do robô com o usuário foi feita por um Tablet utilizando sistema operacional Android. Para tal foi construída uma interface máquina-usuário em que a imagem capturada pela câmera acoplada ao Robô seria vista em tempo real pelo usuário de forma que o mesmo pudesse julgar o alvo e classificá-lo sem o uso a principio de um controle autônomo. O envio se dava através de uma imagem (inicialmente um círculo) capturada pela câmera do 
Tablet e compartilhada com o Manipulador via servidor Samba (Samba 2013). Uma vez que o Manipulador receba a imagem de interesse o sistema de controle e o sistema de identificação por imagens seriam acionados de forma a buscar o objeto enviado pelo Tablet.

A informação do objeto é constituída da imagem do círculo e das coordenadas $(\mathrm{x}, \mathrm{y})$ de seu centroide. Essas coordenadas seriam transformadas em código binário para o controle do robô, direcionando o atuador a um ponto bem próximo ao desejado. Os sistemas de controle e identificação fariam o ajuste fino. Alguns pontos do estudo não foram alcançados, tais como: a construção da interface na câmera nativa do sistema operacional Android, e a redução no tempo do envio da imagem e do seu centroide através do Samba. A interface do usuário havia sido desenvolvida e implementada de forma isolada, utilizando linguagem Java e no ambiente de desenvolvimento Eclipse (Eclipse Foundation 2013). Foi verificado que o tempo de resposta para o envio da imagem e do centroide através do Samba foi de 4 segundos (medida realizada utilizando um cronômetro digital de três dígitos acionados manualmente), inviabilizando o uso do Samba para transmissão dos sinais.

Desta forma, uma segunda estratégia foi adotada, consistindo na utilização de uma comunicação sem fio aplicando microcontroladores PIC. A ideia consistiu em criar uma rede sem fio em que a eletrônica do robô fizesse comunicação direta com a interface do usuário sem necessitar de uma triagem entre programas para envio e recebimento de informações. Para este desenvolvimento foram utilizados: a placa de desenvolvimento Explorer 16 da empresa Microchip; o ambiente de desenvolvimento MPLAB (V.8.84) (Microchip 2012); o módulo Wifi MRF24WB0MA (Microchip 2013); o PIC 24FJ128; e um roteador wireless comum e o gravador e depurador PICKIT 3, também da empresa Microchip.

$\mathrm{O}$ desenvolvimento foi feito conectando-se a placa Explorer 16 à entrada USB do computador. O depurador e o módulo wifi são conectados à esta placa. Inicialmente, ao liga-la pode-se visualizar no monitor da mesma um programa base da Microchip executando e apresentando tipos de funções que podem ser feitas ou desenvolvidas. A partir desse ponto, iniciamos o ambiente de desenvolvimento MPLAB (V.8.84). De inicio, a placa já é reconhecida juntamente com o depurador. Dependendo da versão utilizada para a IDE será solicitado ou não uma atualização do depurador que é normal e automático. Após esse ponto instalamos o stack TCP/IP (Comer, 1998) da Microchip onde existem bibliotecas e ferramentas para serem utilizadas no projeto, após a instalação já podemos visualizar o mesmo pela IDE. Iniciando o projeto, primeiro devemos configurar o roteador com um login e senha desejados, após esse passo devemos gerar um código de acesso WPA-PSK onde esse código estará o link entre login e senha por código hexadecimal. A partir desse ponto, podemos fazer uma compilação de teste para verificar a comunica- ção entre o módulo wifi e o roteador Wireless, onde o mesmo atribuirá um IP ao módulo. Lembrando que para o manipulador o Ip será sempre o mesmo visto que seria inconveniente desacoplar o pic da eletrônica para a verificação do Ip na placa Explorer 16, ou seja, é possível colocar um Ip fixo ou dinâmico no projeto.

Partindo do principio que já obtivemos comunicação entre o módulo e o roteador podemos continuar criando um controle básico na aplicação main do código onde inserimos os acesso das portas do pic e as funções que queremos que ele execute. Para ficar claro, podemos fazer controle de PWM, potenciômetros e acionamentos de outros equipamentos, lembrando sempre que para cada função a mais faz-se necessário o conhecimento dos periféricos do pic selecionado para certificar-se que o mesmo da suporte a tais funções.

Podemos verificar no visor da placa, que um ip foi atribuído ao módulo Wifi e o mesmo já pode ser visto por qualquer máquina conectada a rede ou, no nosso caso o tablet. Basta acessa-lo e pronto temos total permissão e controle das funções que criamos anteriormente. Porém, para que essas funções possam ser visualizadas pelo usuário na tela do seu computador ou tablet, faz-se necessário a criação de uma página Web que podemos alocar dentro da memória do pic. Para o projeto não é necessário a criação de um página Web detalhada, apenas com botões de controle para as funções criadas na aplicação Main, visto que dispomos de uma quantidade limitada de memória. Vale lembra também que o nosso módulo não é desenvolvido para comunicação massiva de dados, ou seja, a velocidade não é suficientemente grande para esse fim, apesar de podermos conectar funções como exemplo email pelo pic.

\section{Ferramenta utilizada}

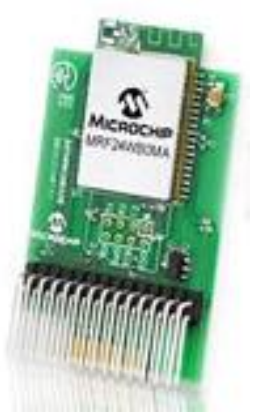

Figura 2. Módulo MRF24WB0MA, imagem retirada do site Micrichip 
Figura 3. Esquema MRF24WB0MA, imagem retirada do site Micrichip

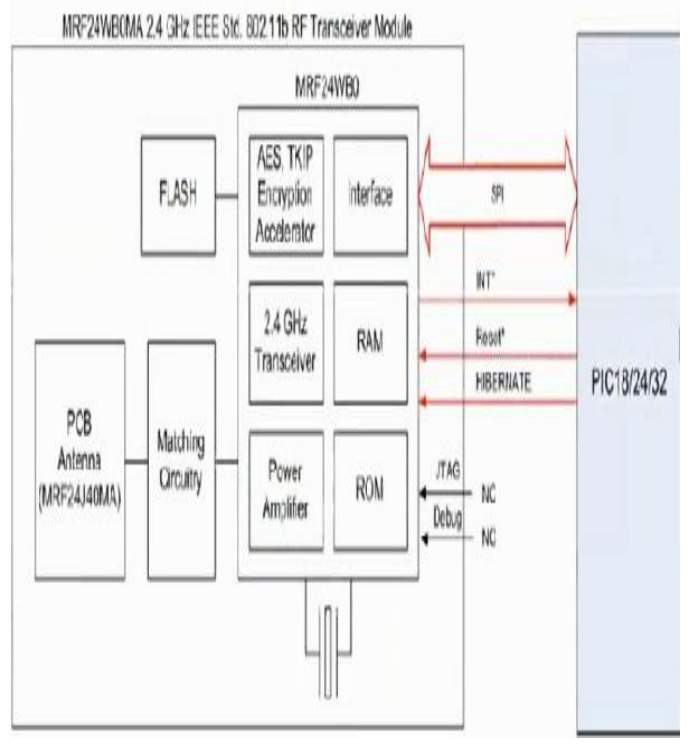

Especificações da Ferramenta

- $\quad$ WI-FI para aplicações embarcadas

- Modulo certificado pela FCC,IC,ETSI,ARIB e Wifi Alliance

- Já inclui o Mac ,banda base, RF e Pa

- Fácil integração com processadores 8/16/32bit

- $\quad$ Suporte nos padrões 1 e $2 \mathrm{Mb} / \mathrm{s}, 802.11 \mathrm{~b}$

- Suporte em modos ad-hoc e AP

- Antena integrada

- Suporte antena externa

- $\quad$ Segurança (WEP,WPA-PSK,WPA2-PSK)

- Programa base Microchip TCP/IP Stack

\section{Fluxograma}
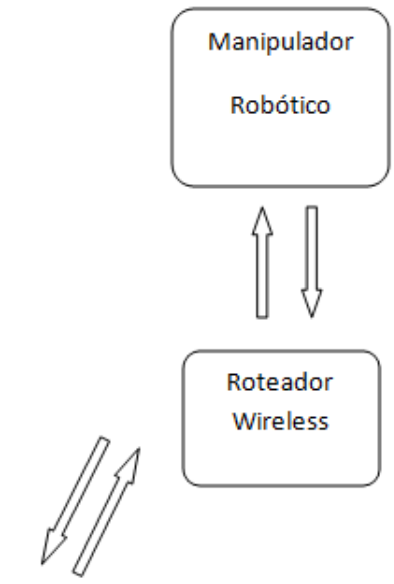

Computador

Tablet
O fluxograma demonstra de forma breve o funcionamento da rede. Onde o roteador faz a comunicação entre computadores e o robô de forma direta sem intermédio de outro programa. Lembrando que o módulo pode ser acessado por mais de uma computador porém na programação podemos limitar esse número para um único equipamento por vez, para que não haja interferência de informações nos comando.

\section{Resultados}

Após analise e comparação feita entre o uso do servidor samba e o módulo wifi, verificou-se que o tempo de resposta é muito mais rápido pelo segundo método, constatado por cronometro digital marcado manual mente, enquanto o uso do servidor samba levou em média de três segundos a quatro segundos, o tempo de resposta do módulo é de menos de 1 segundo, também marcado por cronometro digital de três dígitos.

Dessa forma atendeu ao projeto o fato de o tempo de resposta ser de menos de 1 segundo, pois a ideia é que o reconhecimento seja em tempo real e para isso necessita de uma comunicação que atenda essas exigências.

$\mathrm{O}$ artigo pode ser visto de como uma ferramenta para criação de projetos de controle por redes sem fio de forma simples e objetiva. Podemos utilizar, por exemplo, em qualquer equipamento que tenha conexão com a rede local seja ela uma lâmpada simples ou até mesmo o controle de nível de uma caixa de água. 


\section{Conclusão}

Visto que dois métodos foram utilizados, um primeiro sendo feito pelo sistema operacional Android utilizando a IDE Eclipse e um tablet, porém foram encontrados alguns impedimentos por esse caminho, o que nos levou ao desenvolvimento de uma rede sem fio que pudesse estabelecer comunicação direta com o manipulador robótico via microcontroladores PIC e um Módulo wifi unidos via roteador wireless comum. Desta forma nos trouxe mais benefícios e simplicidade ao projeto.

\section{Agradecimentos}

Doutor Gilberto Alexandre Castello Branco por nortear o desenvolvimento do projeto.

Agradeço a FAPERJ por financiar e acreditar no potencial do projeto.

\section{Referências Bibliográficas}

Comer, D. E. (2007) Redes de Computadores e Internet. São Paulo: Bookman. $4^{a}$ Edição. 632p.

Comer, D. E. (1998) Interligação em rede com TCP/IP: princípios, protocolos e arquiteturas. Rio de Janeiro: Campus. $3^{\mathrm{a}}$ Edição. Vol 1.700p.

Forouzan, B. A. (2008) Comunicação de dados e redes de computadores. São Paulo: Mcgraw-hill Interamericana. $\quad 4^{\mathrm{a}}$ Edição. $1168 \mathrm{p} . \quad$ Microchipwww.microchip.com

Microchip (2012) MPLAB® X IDE User's Guide. Acesso em: Junho 2013. Disponível em: <www.microchip.com>

Microchip (2013) MRF24WB0MA / MRF24WB0MB Data Sheet $2.4 \mathrm{GHz}$ IEEE $802.11 b^{\text {TM }}$. Acesso em: Junho 2013. Disponível em: $<$ http://ww1.microchip.com/downloads/en/DeviceDo c/70632C.pdf $>$

Samba (2013) Samba: Opening windows to a wider world. Acesso em: Junho 2013. Disponível em: <http://www.samba.org/>

Eclipse Foundation (2013) Eclipse Documentation. Acesso em: Junho 2013. Disponível em: < http://www.eclipse.org/documentation/> 